\section{Clinical Patterns of Heparin Allergy: Cross-reactivity Between Low-Molecular-Weight Heparins and Unfractionated Heparins}

Rodríguez-Fernández A, Sánchez-Domínguez M, TorradoEspañol I, Noguerado-Mellado B, Rojas-Pérez-Ezquerra P Allergy Department, Hospital General Universitario Gregorio Marañón, Madrid, Spain

J Investig Allergol Clin Immunol 2019; Vol. 29(2): 132-134 doi: 10.18176/jiaci.0342

Key words: Unfractionated heparins (UFH). Low-molecular-weight heparins (LMWH). Intradermal tests (IDT). Single-blind challenge test (SBCT). Negative predictive value (NPV).

Palabras clave: Heparinas no fraccionadas. Heparinas de bajo peso molecular. Test intradérmicos. Prueba de provocación simple ciego. Valor predictivo negativo.

Heparins are important anticoagulants used in the prophylaxis and treatment of thromboembolic disorders [1]. They include unfractionated heparins (UFHs) and lowmolecular-weight heparins (LMWHs).

Hypersensitivity reactions to LMWHs are not uncommon. Delayed-type hypersensitivity reactions are the most frequently reported [2]. Immediate reactions to UFH and LMWHs have also been reported [3]. Furthermore, these agents can trigger type 2 hypersensitivity reactions (thrombocytopenia) and type 3 reactions (Arthus reaction) [4].

Little is known about cross-reactivity between heparins; therefore, tolerance must always be demonstrated. Tolerance does not seem to depend on molecular weight [5].

Twenty-five patients with a history of hypersensitivity reactions to LMWHs were diagnosed with heparin hypersensitivity in our Allergy Department between 2013 and 2017.

We recorded age, sex, clinical patterns, culprit drug, skin test results, and single-blind challenge tests (SBCTs) performed.

We performed intradermal testing (IDT) with the culprit LMWH (Table), UFH, and a battery of LMWHs, using the same concentrations as that of the original undiluted drug. Readings were taken after 20 minutes and at 48 and 96 hours in the case of delayed reactions and after 20 minutes in immediate reactions.

In delayed reactions, the SBCT was performed with LMWH (subcutaneous administration), and the therapeutic dose was reached in several days.

In order to prove tolerance to UFHs, the drug was administered at increasing doses at intervals of 48 hours. On the first day, we administered $25 \%$ of the therapeutic dose, followed 60 minutes later by another $25 \%$ of the total dose. Fifty percent of the total dose was administered 48 hours later. The other $50 \%$ of the total dose was given 1 hour later (maximum $70 \mathrm{IU} / \mathrm{kg}, 5000 \mathrm{IU}$ ).

Female sex, older age, and longer exposure to heparins seem to be risk factors for heparin allergy [6].

We found enoxaparin to be the most frequent heparin involved in delayed reactions $(80.76 \%)$. Bemiparin was

Table. Single-Blind Challenge Test Results

\begin{tabular}{|c|c|c|c|c|}
\hline No. & Heparin Involved & Diagnosis & $\begin{array}{c}\text { IDT } \\
\text { with UFH }\end{array}$ & $\begin{array}{c}\text { SBCT } \\
\text { with UFH }\end{array}$ \\
\hline 1 & Enoxaparin & IDT & + & NP \\
\hline 2 & Enoxaparin & SBCT & - & + \\
\hline 3 & $\begin{array}{l}\text { Enoxaparin } \\
\text { and bemiparin }\end{array}$ & IDT & + & NP \\
\hline 4 & Enoxaparin & Clinical history & - & - \\
\hline 5 & Enoxaparin & IDT & + & - \\
\hline 6 & Enoxaparin & IDT & - & + \\
\hline 7 & Enoxaparin & IDT & + & - \\
\hline 8 & Enoxaparin & Clinical history & - & + \\
\hline 9 & Bemiparin & SBCT & - & - \\
\hline 10 & Enoxaparin & IDT & - & - \\
\hline 11 & Enoxaparin & IDT & - & - \\
\hline 12 & Bemiparin & IDT & - & - \\
\hline 13 & Enoxaparin & IDT & - & - \\
\hline 14 & Unknown & IDT & - & + \\
\hline 15 & bemiparin & IDT & - & NP \\
\hline 16 & Enoxaparin & IDT & - & - \\
\hline 17 & bemiparin & IDT & - & - \\
\hline 18 & Enoxaparin & IDT & - & NP \\
\hline 19 & $\begin{array}{l}\text { Enoxaparin } \\
\text { and bemiparin }\end{array}$ & IDT & - & - \\
\hline 20 & Enoxaparin & IDT & + & NP \\
\hline 21 & Bemiparin & IDT & + & NP \\
\hline 22 & Enoxaparin & Clinical history & - & - \\
\hline 23 & Enoxaparin & Clinical history & - & - \\
\hline 24 & Enoxaparin & SBCT & - & - \\
\hline 25 & Enoxaparin & IDT & - & - \\
\hline
\end{tabular}

Abbreviations: IDT, intradermal test; NP, not performed; SBCT, single-blind challenge test; UFH, unfractionated heparin; +, positive; - , negative. 
the culprit in $19.23 \%$ of delayed reactions and in $100 \%$ of immediate reactions.

A total of 25 patients were diagnosed with heparin allergy (19 females [76\%], 6 males [24\%]). The mean (SD) age was 68.8 (14.45) years (median, 72.5 ). Only $26.92 \%$ had a personal history of atopy. The most common clinical pattern in the 25 patients diagnosed with LMWH allergy from the total number of delayed reactions $(92 \%)$ was local erythematous plaques $(73.91 \%)$. The other $26.08 \%$ of reactions mostly involved maculopapular exanthema. We registered only 2 cases $(8 \%)$ of type 1 immediate reactions, both consisting of urticaria.

All patients underwent IDT with the culprit agent and a battery of LMWHs including enoxaparin, bemiparin, nadroparin, dalteparin, tinzaparin, fondaparinux, and heparin sodium. The result was positive with enoxaparin in 16 cases $(64 \%)$, with bemiparin in $13(52 \%)$, with nadroparin in 18 $(78.26 \%)$, with dalteparin in $15(65.21 \%)$, and with tinzaparin in $18(78.26 \%)$. All IDT results with fondaparinux were negative, although IDT results with heparin sodium were positive in 6 patients $(24 \%)$.

SBCT was performed with several drugs according to the clinical history of the individual patient (Table). Delayed reactions to heparins were diagnosed based on IDT in 16 patients $(69.56 \%)$, a suggestive clinical history in 4 patients $(17.39 \%)$, and a positive SBCT result in $3(13.04 \%)$.

Of the 23 patients diagnosed with delayed LMWH allergy, SBCT with UFHs performed in 15 patients yielded negative skin test results. The SBCT was positive in 3 of 15 patients $(20 \%)$. All 3 patients presented maculopapular exanthema. The negative predictive value for IDT was $80 \%$.

Two cases of immediate reaction were diagnosed based on a positive IDT result. SBCT with UFHs was negative in both. The negative predictive value for IDT was $100 \%$, although the number of cases was too small to confirm this finding.

Hypersensitivity reactions to heparins are not uncommon, with delayed reactions being more frequent than immediate reactions.

Tolerance to fondaparinux is well known in patients who react to LMWHs [7].

Intravenous SBCT with UFHs was well tolerated in most cases, as reported elsewhere [8].

Pföhler et al [9] performed an intravenous challenge test with UFHs in 10 patients with a history of delayed reactions due to LMWH allergy. The drug was well tolerated in all cases. Gaigl et al [10] performed an intravenous challenge test with UFHs in 28 patients with a history of heparin sodium allergy after subcutaneous injection; all 28 patients tolerated the drug, possibly as a result of the difference in antigen processing and presentation and preferential homing of selectively sensitized lymphocytes in the dermis, but not in other locations. Pföhler et al reported data on 15 patients diagnosed with delayed reactions to LMWHs of whom SBCT with UFHs was performed in 10, all of whom tolerated the drug. Gaigl et al carried out an SBCT with intravenous UFHs in 28 patients with subcutaneous UFH allergy, and all patients tolerated the drug well. Not performing SBCT with UFHs is a viable option, since this is a complicated challenge test requiring intravenous administration.
Nevertheless, it is noteworthy that of the total number of delayed reactions in our study, 6 patients had a positive IDT result with UFHs, and 3 had positive results with SBCT, with total cross-reactivity between LMWHs and UFHs of $36 \%$ and $26 \%$ respectively. Therefore, cross-reactivity between LMWHs and UFHs is not uncommon.

IDT results are very useful for diagnosis, but they are not diagnostic in $100 \%$ of cases, with SBCT remaining the gold standard test in drug allergy.

Since UFH continues to be the heparin with the shortest half-life and the easiest to monitor during interventions, skin tests and SBCTs with UFHs should be performed in all patients with confirmed allergy to LMWHs.

The cross-reactivity we observed indicates the need to confirm tolerance to UFHs in patients diagnosed with heparin allergy.

In patients with allergic reactions to LMWHs, a full allergy work-up should be performed with skin tests and SBCT based on UFHs and all available LMWHs.

\section{Funding}

This study was funded by the Spanish National Health system.

\section{Conflicts of Interest}

The authors declare that they have no conflicts of interest.

\section{References}

1. Alban S. From heparins to factor Xa inhibitors and beyond. Eur J Clin Invest. 2005;35:12-20.

2. Trautmann A, Seitz CS. Heparin allergy: delayed-type non-IgEmediated allergic hypersensitivity to subcutaneous heparin injection. Immunol Allergy Clin North Am. 2009;29:469-80.

3. Cesana P, Scherer K, Bircher AJ. Immediate Type Hypersensitivity to Heparins: Two Case Reports and a Review of the Literature. Int Arch Allergy Immunol. 2016;171:285-9.

4. Jappe U, Reinhold D, Bonnekoh B. Arthus reaction to lepirudin, a new recombinant hirudin, and delayed-type hypersensitivity to several heparins and heparinoids, with tolerance to its intravenous administration. Contact Dermatitis. 2002;46:29-32.

5. Weberschock T, Meister AC, Bohrt K, Schmitt J, Boehncke WH, Ludwig RJ. The risk for cross-reactions after a cutaneous delayed type hypersensitivity reaction to heparin preparations is independent of their molecular weight: a systematic review. Contact Dermatitis. 2011;65:187-94.

6. Grims RH, Weger W, Reiter H, Arbab E, Kränke B, Aberer W. Delayed-type hypersensitivity to low molecular weight heparins and heparinoids: cross-reactivity does not depend on molecular weight. Br J Dermatol. 2007;157:514-7.

7. Schindewolf $M$, Scheuermann J, Kroll $H$, Garbaraviciene J, Hecking C, Marzi I, et al. Low allergenic potential with Fondaparinux: results of a prospective investigation. Clin Proc. 2010;85:913-9.

8. Maroto-litani M, Higaki Y, Kawashima M. Cutaneous allergic reaction to heparins: subcutaneous but not intravenous provocation. Contact Dermatitis. 2005;52:228-30. 
9. Pföhler C, Müller C, Pindur G, Eichler G, Schäfers HJ, Grundmann U, et al. Delayed-Type Heparin Allergy: Diagnostic Procedures and Treatment Alternatives.VA Case Series Including 15 Patients. WAO Journal. 2008;1:194-9.

10. Gaigl Z, Pfeuffer P, Raith R, Brocker EB, Traumann A. Tolerance to intravenous heparin in patients with delayedtype hypersensitivity to heparins: a prospective study. $\mathrm{Br} J$ Haematol. 2005;128:389-92.

1 Manuscript received September 26, 2018; accepted for publication October 16, 2018.

Ana Rodríguez Fernández Allergy Department Hospital General Universitario Gregorio Marañón E-mail: anarf@me.com 